\title{
Memahami Hubungan antara Komitmen Afektif dan Kominten Kontinuans pada Perguruan Buddhi Tangerang
}

\author{
Petrus T Resi \\ Manajemen, Universitas Buddhi Dharma, Banten, Indonesia
}

\begin{abstract}
ABSTRAK
Penelitian ini bertujuan untuk mengetahui pengaruh komitmen afektif terhadap komitmen berkelanjutan di Perguruan Buddhi Tangerang. Responden diambil dari guru dua sekolah yaitu SMP (SMP) dan SMA (SMA). Dari 40 kuesioner yang disebarkan, 32 orang benar-benar terisi dan dikirim kembali ke peneliti yang kemudian dianalisis dan ditafsirkan secara statistik. Hasilnya menunjukkan bahwa komitmen afektif tidak berpengaruh terhadap komitmen kontinu. Dengan kata lain, orang bekerja dan tinggal dalam sebuah organisasi tidak berarti mereka memiliki keterikatan emosional dengan organisasi. Sebaliknya, mereka tetap bertahan karena alasan ekonomi. Mereka bertahan karena manfaat yang mereka dapatkan dari organisasi. Mereka bertahan karena kehilangan pengalaman jika mereka keluar dari organisasi dan kurangnya pekerjaan alternatif.
\end{abstract}

Kata kunci: komitmen afektif; komitmen berkelanjutan; perguruan buddhi

\section{Understanding the Relationship between Affective Commitment and Continuity Commins at Buddhi College Tangerang}

\begin{abstract}
This research is aimed at identifying the influence of affective commitment on continuance commitment at Perguruan Buddhi Tangerang. The respondents were taken from teacher of two schools namely SMP (junior high school) and SMA (senior High School). From 40 questionnaires distributed, 32 were completely filled and sent back to researchers which are then statistically analyzed and interpreted.The result shows that affective commitment has no influence on continuance commitment. In other word, people work and stay in an organization doesn't mean that they have emotional attachment with the organization. Rather, they stay more because of economic reason. They stay because the benefir that they gain from the organization. They stay because the lost they experience if they quit the organization and lack of alternative employment.
\end{abstract}

Keyword: affective commitment; continuance commitment; perguruan buddhi 


\section{PENDAHULUAN}

Penelitian terdahulu menunjukan bahwa gambaran komitmen para guru SMP dan SMA Buddhi hanya mencapai tingkat ratarata, tidak sangat tinggi dan tidak sangat rendah (Resi, 2015). Di mana rata-rata komitmen afektif yang tertinggi diikuti dengan komitmen normative dan komitmen kontinuans yang terendah. Penelitian lain memperlihatkan bahwa hubungan antara tenor (masa kerja) dengan komitmen organisasi dari kedua lembaga yang sama juga tidak kuat dan pengaruhnya tidak begitu signifikan. Ini terutama sangat terlihat ketika kita mencermati hubungan dan pengaruh tenor terhadap masing-masing dari tiga komponen komitmen organisasional (afektif, normative, dan kontinuans) (Resi dkk., 2016)

Selanjutnya Lin dan Wang (2012) menemukan bahwa di antara para karyawan hotel di Taiwan, komitmen afektif bukan hal yang penting bagi terbentuknya komitmen kontinuans mereka, dengan kata lain, kedua komponen komitmen ini tidak saling mempengaruhi, oleh Allen dan Meyer diseut sebagai empirically distinguishable (Allen and Meyer, 1990, p.1) Dengan mengaitkan kedua temuan di atas, penulis mengajukan sebuah pertanyaan yang menjadi landasan di dalam melakukan penelitian ini. Pertanyaan tersebut adalah: "bagaimana hubungan antara komitmen afektif terhadap komitmen kontinuans pada guru-guru di SMP dan SMA Perguruan Buddhi.

Tujuan dari penelitian ini dengan demikian adalah untuk mengetahui adakah hubungan antara komitmen afektif terhadap komitmen kontinuans. Manfaat yang dapat diperoleh dengan mengetahui hubungan ini bagi manajemen adalah dapat menentukan langkah yang tepat di dalam meningkatkan kebijakan yang dapat meningkatkan kedua komponen komitmen organisasi ini. Jadi misalnya penelitian ini memberikan hasil yng sama seperti yang dilakukan oleh Lin dan Wang atau sebagaimana ditengarai oleh Allen dan Meyer sebagai distinguishable maka kebijakan manajerial juga akan berbeda dibandingkan jika mereka itu merupakan komponen yang penting satu bagi yang lain.

\section{TINJAUAN PUSTAKA}

Robbins dan Judge (2007: 74) mendefinisikan komitmen afekstif sebagai "an emotional attachment to the organization and a belief on its values". Sementara 
komitmen kontinuans diartikan sebagai "the perceived economic value of remaining with an organization compared to leaving it". Jadi satu berkaitan dengan ikatan emosional yang timbul dalam diri seseorang karyawan karena dia yakin atas nilai-nilai yang diperjuangkan organisasi itu sementara yang lainnya berkaitan dengan manfaat ekonomi yang diperoleh dan akan sangat merugikan kalau dia meninggalkan organisasi di mana dia bekerja. Jelas bahwa komitmen mereka kepada sebuah organisasi sangat berbeda. Disini terlihat bahwa kedua konsep ini merupakan konsep yang "distinguishable".

Meyer dan Allen (1984) pada mulanya menggambarkan komitmen organisasional terdiri dari dua dimensi yakni afektif dan kontinuans. Mereka mendefinisikan komitmen afektif sebagai "positive feelings of identification with, attachment and involvement in the work organization'; dan komitmen kontinuans sebagai "the extend which employees feel committed to their organization by virtue of the costs that they feel are associated with leaving" (1984: 375). Dimendsi ketiga yakni komitmen normative baru ditambahkan mereka pada setelah melakukan penelitian leih lanjut (1990). Pertanyaannya adalah apakah keduanya saling memperngaruhi? Kalau ada, bagaimanakah arah pengarusnya? Lin dan Wang (2012) menemukan bahwa karyawan memperlihatkan afektif komitmen yang cukup tinggi tetapi lebih disebabkan oleh persepsi mereka akan ketiadaan alternative pekerjaan yang lain. Disamping itu mereka juga tidak menganggap bahwa nilai organisasi mirip dengan nilai yang mereka anut sebagai individu. Sebaliknya mereka tetap bekerja dengan organisasi mereka karena meraka menganggap bahwa banyak manfaat yang bias mereka peroleh dari organisasi mereka bekerja. Atau dengan kata lain, banyak kerugian yang mereka alami kalau mereka berhenti bekerja di organisasi tersebut.

Karyawan meneruskan pekerjaan di sebuah organisasi bukan karena komitmen afektif tetapi karena adanya manfaat yang tinggi yang dapat diperoleh dan ketiadaan alternative pekerjaan lain. Hal ini sejalan dengan Becker (1960) bahwa orang memiliki komitmen atas sebuah tindakan karena biaya berkenaan dengan perilaku sebaliknya adalah begitu tingginya, bukan karena mereka memiliki ikatan afektif dengan objek komitmen mereka. McGee dan Ford (1987) juga menemukan bahwa karena alternative pekerjaan yang 
menyebabkan karyawan tetap bekerja pada sebuah organisasi. Karyawan seperti ini memperlihatkan komitmen yang berbeda ketimbang pandangan afektif. Beck dan Wilson (2000) juga mengemukakan bahwa komitmen kontinuans hanyalah merupakan ikatan instrumental kepada sebuah organisassi, di mana asosiasi diri dengan organisasi hanya diudasarkan kepada manfaat ekonomis yang diperoleh. Jadi sangat bergantung pada imbalan ekstrinsik positif tanpa memandang tujuan-tujuan dan nilainilai organisasi. Kekuatan komitmen kontinuans sangat ditentukan poleh biaya meninggalkan organisasi yang dipersepsikan (Meyer dan Allen, 1984).

Kesimpulan dapat dibuat bahwa komitmen kontinuans disebabvkan oleh biaya yang tinggi akibat meninggalkan sebuah organisasi. Bukan akibat dari adanya ikatan emosional yang dipandang sebagai asosiasi atau identifikasi diri atas tujuan dan nilai-nilai oirganisasi. Sebagaimana Meyer dkk (1990: 715) mengatakan bahwa "accrued investments and poor employment alternatives tend to force individuals to maintain their line of action and are responsible for these individuals being committed because they need to."
Dengan demikian hipotesis yang bias ditarik dalam penelitian ini adalah: diduga bahwa komitmen afeksi tidak mempunyai penraguh terhadap komitmen kontinuans. Atau dengan kata lain komitmen afeksi tidaklah penting bagi komitmen konstonuans.

\section{METODOLOGI PENELITIAN}

Penelitian ini dilakukan pada dua sekolah lanjutan yakni SMP dan SMA Perguruan Buddhi di Kota Tangerang. Pertimbangan menggunakan dua sekolah ini sebagai objek penelitian menurut penilaian penulis adalah karena kedua sekolah ini memiliki budaya organisasi (corporate culture) yang kuat dimana nilai utama organisasi dianut secara luas oleh anggota-anggotanya, dan ini mempengaruhi perilaku para anggota organisasi tersebut (Robbins 1998, p. 598). Salah satu cirri khas dari budaya yang kuat adalah kekompakan para anggotanya dalam bentuk kebersamaan di dalam melakukan kegiatan-kegiatan.

Responden dalam penelitian ini adalah para guru SMP dan SMA Perguruan Buddhi. Dari total sekitar 40 orang guru, hanya $32(80 \%)$ yang mengembalikan kuesioner yang telah diisi dengan baik. Dalam hal ini dilakukan secara sensus. 
Untuk memperolah data penulis menggunakan kuesioner yang diadopsi dari Alllen and Meyer (1990; pp 6 - 8). Instrument ini dapat dilihat di lampiran laporan penelitian ini. Data yang telah diiperoleh selanjutnya diolah dengan menggunakan program SPSS. Selanjutnya penulis melakukan intrepetasi atas hasil yang diperoleh sebagai output dari program SPSS tersebut di dalam rangka menjawab masalah pokok penelitian ini.

\section{HASIL DAN PEMBAHASAN}

Tabel 1: Descriptive Statistics

\begin{tabular}{|l|l|l|l|}
\hline & Mean & Std. Deviation & $\mathrm{N}$ \\
\hline $\begin{array}{l}\text { KomitmenKont } \\
\text { inuans } \\
\begin{array}{l}\text { KomitmenAfek } \\
\text { tif }\end{array}\end{array}$ & 22.5625 & 4.50045 & 32 \\
\hline
\end{tabular}

Tabel statistic deskriptif menunjukan bahwa rata-rata jawaban mereka atas kuesioner menyangkut komitmen kontinuans, delapan butir, yang diajukan adalah hanya sebesar 22,56 dari maksimum 40, dengan deviasi standar 4,5. Ini artinya dari skala 1 sampai 5, rata-rata jawaban mereka bahkan tidak sampai 3 untuk setiap butir pernyataan. Sedangkan untuk komitmen afektif, rata-rata jawaban responden adalah 27,47 dengan deviasi standar sebesar 2,9. Berarti rata-rata
Dari uraian di atas dapat diketahui bahwa komitmen afektif responden hanyalah rata-rata (sedang). Booleh dikatakan komitmennya tidak begitu positif. Artinya mereka mungkin saja tetap bekerja tetapi dengan tingkat afeksi yang rendah, ikatan emosional tidak begitu kuat. Lebih-labih lagi dengan komitmen kontinuans, orang boleh saja masih bekerja pada organisasi tersebut tetapi tidak merasakan sebagai sebuah kewajiban yang harus diperjuaqngkan mati-matian. Begitu juga mereka akan dengan mudah meninggalkan organisasi sekarang kalau mereka mendapat tawaran pekerjaan di luar yang lebih baik.

Tabel 2: Correlations

\begin{tabular}{|ll|l|l|}
\hline & & $\begin{array}{l}\text { Komitmen } \\
\text { Kontinuans }\end{array}$ & $\begin{array}{l}\text { Komitmen } \\
\text { Afektif }\end{array}$ \\
\hline $\begin{array}{l}\text { Pearson } \\
\text { Correlation }\end{array}$ & $\begin{array}{l}\text { Komitmen } \\
\text { Kontinuans } \\
\text { Komitmen } \\
\text { Afektif }\end{array}$ & 1.000 & -.063 \\
\hline Sig. (1-tailed) & $\begin{array}{l}\text { Komitmen } \\
\text { Kontinuans } \\
\text { Komitmen } \\
\text { Afektif }\end{array}$ & 1.000 \\
\hline $\mathrm{N}$ & $\begin{array}{l}\text { Komitmen } \\
\text { Kontinuans } \\
\text { Komitmen } \\
\text { Afektif }\end{array}$ & 32 & .367 \\
\hline
\end{tabular}

Penting juga diketahui hubungan antara komitmen afektif dengan komitmen 
kontinuans. Dengan kata lain apakah ikatan emosional dengan organisasi mempengaruhi kesediaan seseoraqng untuk tetap mempertahaankan keanggotaannya dengan organisasi tersebut?

Dari hasil perhitungan pada table correlations di atas terlihat bahwa komitmen afeksi memperlihatkan hubungan negative dengan komitmen kontinuans. Ini berarti bahwa memiliki ikatan emosional dengan organisasi ini tidak serta merta membuat seseorang tetap ingin bekerja di organisasi tersebut.

Tabel 3: Model Summary

\begin{tabular}{|c|c|c|c|c|c|c|c|c|c|}
\hline \multirow[b]{2}{*}{$\begin{array}{l}\text { Mod } \\
\mathrm{el}\end{array}$} & \multirow[b]{2}{*}{$\mathrm{R}$} & \multirow[b]{2}{*}{$\begin{array}{l}\mathrm{R} \\
\text { Squa } \\
\text { re }\end{array}$} & \multirow[b]{2}{*}{\begin{tabular}{|l} 
Adjust \\
ed r R \\
Squar \\
e
\end{tabular}} & \multirow[b]{2}{*}{$\begin{array}{l}\text { Std. } \\
\text { Error } \\
\text { of the } \\
\text { Estim } \\
\text { ate }\end{array}$} & \multicolumn{5}{|c|}{ Change Statistics } \\
\hline & & & & & \begin{tabular}{|l} 
R \\
Squa \\
re \\
Chan \\
ge
\end{tabular} & \begin{tabular}{|l} 
F \\
Chan \\
ge
\end{tabular} & $\begin{array}{l}\mathrm{df} \\
1\end{array}$ & $\begin{array}{l}\mathrm{df} \\
2\end{array}$ & $\begin{array}{l}\text { Sig. F } \\
\text { Chan } \\
\text { ge }\end{array}$ \\
\hline 1 & $\begin{array}{l}.06 \\
3^{a}\end{array}$ & .004 & -.029 & $\begin{array}{l}4.5658 \\
3\end{array}$ & .004 & .118 & 1 & 30 & .733 \\
\hline
\end{tabular}

a. Predictors: (Constant), KomitmenAfektif

Dari Model Summary terlihat bahwa dengan koefisien korelasi 0,063 yang berarti hampir tidak ada hubungan antara komitmen afektif dan kontinuans, dapat juga diperjelas dengan melihat koefisien determinasi yakni 0,004. Artinya komitmen afektif hanya berpengaruh $0,4 \%$ terhadap komitmen kontinuans.

Hal ini bermakna bahwa kedua komponen komitmen organisasi ini dapat dibedakan satu sama lain, oleh karena itu mempengaruhi anteseden masing-masing variable dapat diilakukan secara terpisah dan independen. Perlakuan untuk meningkatkan salah satu dari dua komponen komitmen organisasi ini tidak akan berpengaruh terhadap komponen komitmen organisasi yang lain.

Tabel 4: Coefficientsa

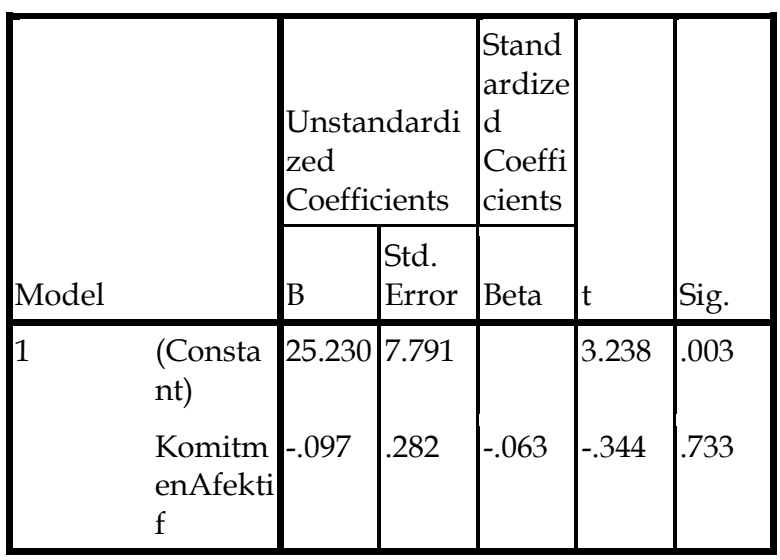

a. Dependent Variable: KomitmenKontinuans

Dari table Coefficients juga terlihat bahwa pengaruh komitmen afektif terhadap komitmen kontinuans juga tidak signifikan terlihat pada koefisien signifikansinya pada 0,733 jauh lebih besar dari standar error yang digunakan yakni 0,05.

\section{KESIMPULAN DAN IMPLIKASI MANAJERIALNYA}

Kesmpullan: dari semua hasil analisis terlihat bahwa sejalan dengan pendapat para ahli bahwa kedua komponen komitmen organisasional yang digunakan 
di dalam penelitian ini adalah dua komponen yang terpisah atau "distinguishable". Oleh karena itu bias dicari korelasinya antara mereka $b$ erdua. Akan tetapi di dalam penelitian ini ditemukan $\mathrm{b}$ ahwa komitmen afektif tidak begitu penting bagi komitmen continuance. Oleh karena itu meningkatkan sebuah komponen dari kedua kopmponen kmomitmen orgfanisasi ini tidak membawa dampak bagi komponen komitmen organisasi lainnya.

\section{REFERENSI}

Allen, Natalie J. \&Meyer John P. (1990). The measurement and antecedents of affective, continuance and normative commitment to the organization. Journal of Occupational Psychology. 63. 1 - 18.

Beck, K., \& Wilson, C., (2000). Development of Affective Organizational Commitment: A Cross-Sequential Examination Of Change With Tenure. Journal of Vocational Behavior, 56, 114 - 136.

Lin, Chien-Huang \& Wang , Wen-Cheng (2012). The Relationship between Affective and Continuance Organizational Commitment. Journal of Asian Business Strategy, Vol. 2, No. 5, pp. 89-94.

McGee, G. W., \& Ford, R. C., (1987). Two (or more?) dimensions of organizational commitment: Reexamination of the affective and continuance commitment scales.
Journal of Applied Psychology, 72: 638-642).

Meyer, John P., \& Allen, Natalie J., (1984). Testing the "Site-Bet Theory" of Organizational Commitment: Some Methodological Considerations. Journal of Applied Psychology, Vol. 69 No. 3., 372-378.

Meyer, J., P., Allen, N., J., \& Gellaty, I. R. (1990) Affective and Continuance Commitment to the organization: Evaluation of measures and analysis of concurrent and time-lagged relations. Journal of Applied Psychology, 75, 710-720.

Resi, P. T., (2015). Memahami Komitmen organisasi pada Perguruan Buddhi Tangerang. Tidak dipublikasikan.

Resi, P. T., Herijawaty, E \& Anggraeni, R. D., (2016). Hubungan antara Masa Kerja dengan Komitmen Organisasi 0ada perguruan Buddhi Tangerang. Tidak dipublikasikan.

Robbins, Stephen P., \& Judge Timothy A. (2007). Organizational Behavior. $12^{\text {th }}$ edition. Upper Saddle River, New Jersey; Pearson Prentice Hall.

[1] Y. Josephine, "JURNAL TECH-E Implementasi eBudgeting Terhadap Kinerja PT Primer Eka Properti Melalui Pengendalian Internal," Tech-E, vol. 1, no. 1, pp. 1-6, 2017. 